\title{
Companhia Teatro de Seraphim: Artaud, Brecht \& outros seres afins
}

Igor de Almeida Silva

Doutorando em Artes Cênicas/USP

Área de Concentração: Pedagogia do Teatro

Orientadora: Ingrid Dormien Koudela

Bolsista Capes

Professor e pesquisador

Resumo: Este trabalho consiste em um estudo introdutório sobre a Companhia Teatro de Seraphim (CTS), sediada no Recife, em atividade desde março de 1990. Pretende-se observar as relações entre Arte e Política nas proposições estéticas e ideológicas do grupo, tendo como corpus textos de programas de espetáculo, entrevistas, artigos de imprensa, críticas, projetos de montagem, entre outros documentos, priorizando aqueles produzidos pelos integrantes da CTS, como forma de identificar suas ideias teatrais, a partir da poética e do pensamento de Artaud, Brecht, Benjamin, Pirandello e Genet.

Palavras-chave: cultura brasileira, estética, ideais teatrais, teatro brasileiro

Title: Seraphim Theater Company: Artaud, Brecht \& other related beings

Abstract: This work consists of an introductory study on the Seraphim Theater Company (CTS), based in Recife, in operation since March 1990. It intends to observe the relationship between Art and Politics in the aesthetic and ideological propositions of the group, having as corpus texts of show programs, interviews, press articles, reviews, stage setting projects, among other documents, prioritizing the ones produced by members of the CTS as a way to identify their theatrical ideas, starting from the poetic and the thought of Artaud, Brecht, Benjamin, Pirandello and Genet.

Keywords: aesthetic, Brazilian culture, Brazilian theater, theatrical ideas

Título: Compañía Teatro de Seraphim: Artaud, Brecht y otros seres afines

Resumen: Este trabajo consiste en un estudio introductorio sobre la Compañía Teatro de Seraphim (CTS), con sede en Recife, en funcionamiento desde marzo de 1990. La intención es observar las relaciones entre Arte y Política en las propuestas estéticas e ideológicas del grupo, teniendo como corpus textos de programas de espectáculo, entrevistas, artículos de prensa, críticas, proyectos de montaje, entre otros documentos, dando prioridad a los producidos por los miembros de la CTS, como una forma de identificar sus ideas teatrales, a partir de la poética y del pensamiento de Artaud, Brecht, Benjamin, Pirandello y Genet.

Palabras-clave: cultura brasileña, estética, ideas teatrales, teatro brasileño 


\section{O teatro de Séraphin}

A Companhia Teatro de Seraphim (CTS) surge em março de 1990, no Recife, com a estreia do espetáculo Heliogábalo \& eu, de João Silvério Trevisan, direção de George Moura. No mês seguinte, o grupo apresenta um novo espetáculo, a partir de outra obra de Trevisan: Em nome do desejo, adaptação de romance homônimo, sob a direção de Antonio Cadengue, que é um dos fundadores e diretor artístico da CTS.

Originalmente, o grupo se denomina Companhia Teatro de Séraphin, em referência ao livro $O$ teatro e seu duplo, de Antonin Artaud, especificamente ao ensaio "O teatro de Séraphin", que fazia parte dos estudos teóricos preparatórios para a montagem de Heliogábalo \& eu. Na montagem seguinte, opta-se pela forma portuguesa arcaizante "Seraphim", como uma maneira de se manter próximo e distante da raiz francesa "Séraphin", ou italiana "Serafino".

No projeto de encenação de Heliogábalo \& eu, encontra-se um pequeno texto sobre a CTS, de autoria de George Moura, ainda com a grafia Séraphin, que se assemelha a uma carta de intenções, quase um manifesto:

Somos seres afins, Serafins. Afins, inclusive de fazer teatro. Queremos experimentar, lançar um grito, ainda que isso nos esvazie. Representar é uma forma de viver. Quem nos proibiria de acreditar no sonho do teatro quando acreditamos no sonho da realidade? $O$ Teatro de ser afins de fazer Teatro. Pode parecer óbvio, mas jamais obtuso. A alegria mesmo depois de 100 anos do nascimento de Oswald de Andrade - ainda é a prova dos nove. Viva a rapaziada. A nossa busca é pela expressão exata, sem cartilhas ou doutrinas, mas com todo o estudo possível e imaginável. É imprescindível uma estética teatral que leve em consideração as evoluções e revoluções do teatro no mundo. A favor do teatro inteligente. Serafins (seres afins) do Teatro. Detalhar mais seria estragar a poesia da coisa (1990). ${ }^{1}$ [grifos nossos].

Os trechos grifados são justamente os que podem ser identificados como paráfrases de "O teatro de Séraphin". Percebe-se aqui não apenas uma leitura e apreensão do pensamento de Artaud, mas também um projeto coletivo. Assim como procedera Artaud em sua época, a jovem companhia parece tomar para si a questão do teatro-vida, em que representar é uma forma de viver: "Quando vivo não me sinto viver. Mas quando represento sinto-me existir" (ARTAUD, 1999, p. 171). 
Outro aspecto importante do manifesto diz respeito ao rigor na obra artística, que marca a união entre arte e ciência em Artaud: "No teatro, doravante poesia e ciência devem identificar-se" (ARTAUD, 1999, p. 172). Ele pode ser inferido no trecho: $A$ nossa busca é pela expressão exata, sem cartilhas ou doutrina. Objetiva-se o rigor da forma, por meio da pesquisa e do estudo, sem prender-se a fórmulas cristalizadas. Estas palavras rigor, precisão, expressão exata serão frequentemente referenciadas e enfatizadas nos programas dos espetáculos e nas entrevistas dos integrantes do grupo. É uma marca, um posicionamento artístico e, sobretudo, uma procura.

E, nesse posicionamento, deixam claro os Seraphins o teatro que gostam e pretendem fazer: A favor do teatro inteligente. Serafins (seres afins) do Teatro. O jogo linguístico com as palavras "serafim" e "seres afins" traz a ideia de afinidade, união entre pessoas com desejos e modos de pensar comuns, em busca de uma mesma utopia teatral. ${ }^{2}$ Jogo linguístico de sentido gregário, ao mesmo tempo em que deixa claro que o teatro sem pensamento e rigor não lhes interessa, não lhes é "afim".

\section{O teatro da Crueldade}

O teatro da Crueldade expressa o conflito primordial que separa o homem do mundo. A Crueldade, entretanto, não é necessariamente violenta, sangrenta, sádica, física, mas ontológica. Para Artaud, há uma crueldade mais fundamental na Existência que separa o corpo do espírito, aniquilando o homem. Dessa maneira, o teatro da Crueldade é ontológico na medida em que está ligado "ao sofrimento de existir e à miséria do corpo humano" (VIRMAUX, 2000, p. 43).

Segundo Alain Virmaux, "Essa visão da condição humana em uma perspectiva de contínuo dilaceramento pode ser denominada gnóstica” (2000, p. 43). Ou seja, uma visão que concebe o universo de modo dualístico, na qual a matéria (em particular, o corpo humano) é considerada essencialmente má e, por isso mesmo, templo de padecimento. É contra essa maldade cósmica que Artaud e seu teatro da Crueldade se insurgem, objetivando a reconstrução desse homem dilacerado, em que a Cultura é apartada da Vida: "Uso a palavra crueldade no sentido de apetite de vida, de rigor cósmico e de necessidade implacável, no sentido gnóstico de turbilhão de vida que devora as trevas, no sentido da dor fora de cuja necessidade inelutável a vida não 
consegue se manter; o bem é desejado, é o resultado de um ato, o mal é permanente" (ARTAUD, 1999, p. 119).

Essa tentativa de reabilitação do Ser em Artaud pode ser identificada, pelo menos, em dois espetáculos da Companhia Teatro de Seraphim: Em nome do desejo (1990/1992) e Noite escura (1997). Baseado no romance homônimo de João Silvério Trevisan, Em nome do desejo apresenta a história de amor entre dois jovens seminaristas. Segundo o encenador, “A ideia é certamente passar através da cena todo o inacreditável montante de contradições presentes no cotidiano de nosso dia a dia, marcado pelo cristianismo enquanto religião que não conseguiu escapar da sensualidade que pretendeu condenar nos pagãos" (1992a). Não se escamoteia a sensualidade carnal dos personagens e nisso reside o dilaceramento de Tiquinho, que se encontra cindido "entre o desejo de amar a Deus sobre todas as coisas e os seus impulsos de amar Abel acima de Deus" (CADENGUE, 1997). O espetáculo é entrecortado por poemas de Santa Teresa de Ávila e São João da Cruz, enunciados pela própria figura de Santa Teresa, que atravessa todo o espetáculo, imprimindo-lhe um erotismo místico.

Santa Teresa de Ávila é retratada novamente pela Seraphim no espetáculo Noite escura, de Paulo Vieira, direção de Antonio Cadengue, em 1997, realizado conjuntamente com o Hospital Ulysses Pernambucano, no Ciclo Iluminuras, em função das discussões em torno da reforma manicomial que acontecia em todo o país. Mais do que a presença de Santa Teresa, o traço de união entre as duas montagens é a dualística entre amor e devoção, erotismo e sacralidade, carne e espírito. O Encenador admite o "parentesco" dos espetáculos, no texto do programa de Noite escura: "Não creio que NOITE ESCURA se assemelhe ao EM NOME, mas com ele guarda certo parentesco texto e encenação - proposital: gosto das imagens que se refletem umas nas outras" (1997).

Em Noite escura, o que vigora é "o testemunho de uma experiência humana do divino - contado, narrado, declamado, gritado, sussurrado, cantado - pondo a nu a trajetória de uma mulher que abandona a luz do sol pelas trevas da noite escura, num processo de purificação" (CADENGUE, 1997). Experiência em si mesma cruel, segundo Artaud, pois este personagem busca uma união profunda com Deus a partir de um mergulho no "abismo noturno" da alma, em que Deus está imanente. Como diz o 
encenador, neste espetáculo, "o ato poético se faz verbo e se constitui como uma celebração da Presença Ausente: daquilo que em nós é trevas, mas ao mesmo tempo gestação do amanhecer" (1997).

Tanto na figura de Santa Teresa quanto nas ideias teatrais desses dois espetáculos estão presentes os pressupostos do Teatro da Crueldade de reconstrução do homem por meio do voltar-se a si mesmo. Assim como Artaud, o encenador empreende uma pedagogia cruel e lúcida em direção ao Ser, revelando o entre-lugar do sagrado e suas contradições na existência interior e na vida cotidiana, na sexualidade juvenil de Tiquinho e Abel, no erotismo místico de Santa Teresa de Ávila, sem nenhuma implicação cristã, mas tentando trazer à cena a força das paixões e dos mitos, o obscuro e o primitivo da natureza humana.

\section{O outro teatro político}

Para Bernard Dort, Brecht promove um teatro de reflexão e análise política da sociedade que busca "uma verdade que ainda está por fazer" (1977, p. 392). Já Massimo Castri diz que Artaud proporciona instrumentos de conhecimento e modificação do indivíduo, sendo este também um componente presente em Brecht. Por isso, Castri acredita que "Las dos líneas teatrales, histórico-materialista y artaudiana, que se presentan historicamente paralelas, y que [...] han sido artificialmente separadas [...] aparecen hoy en realidad como confluentes, momentos complementários de único proceso y tienden a refluir en uma misma operación, la del teatro político" (1978, p. 213).

Afinal, se Brecht propunha o materialismo histórico como instrumento de conhecimento e análise da sociedade, o mesmo fazia Artaud só que partindo e se direcionando para o indivíduo, o inconsciente, o irracional. São metodologias e visões de mundo diferentes que, entretanto, convergem para um mesmo ponto: ambas se propõem como instrumentos de libertação do homem, seja por meio de sua razão crítica, seja por intermédio de todos os seus sentidos. Nisso reside o político no Teatro da Crueldade. Talvez seja por este viés que se possa compreender também o político na Companhia Teatro de Seraphim. 
Em A lira dos vinte anos, espetáculo de 1992, texto de Paulo César Coutinho, direção de Antonio Cadengue, a CTS mergulha na realidade do Brasil de 1968, época conturbada em nossa história nacional, marcada pela repressão do regime militar, instaurado em 1964; época de promulgação do AI-5, coibindo todo o movimento estudantil no país com extrema violência. De cunho quase autobiográfico, o texto trata da trajetória de cinco estudantes que, em 1968, trocam os bancos universitários pela luta armada, procurando não apenas por transformações políticas, mas também existenciais. Ao mesmo tempo em que sonham com a Revolução, descobrem o amor e o sexo.

De acordo com o encenador, a intenção deste espetáculo "é delinear no palco recifense, no ano de 1992, um projeto histórico-político-existencial, preocupado em lançar uma ponte entre o agora e o antes, para que o antes não fique sem futuro e o agora não fique sem passado. Pois o presente sempre corre o risco de não ter sentido, se não se enraizar numa anterioridade significativa" (1992b). O encenador tenta acrescentar à abordagem deste passado recente, além do histórico e do político, o existencial, o humano, a sexualidade, o amor. Essas características já se encontravam presentes no texto; contudo, estes últimos aspectos foram acentuados na encenação. É o que atesta a crítica Maria Lúcia Pereira, sobre texto e encenação, em sua apreciação ao espetáculo:

Sua peça [de Paulo César Coutinho] trata em pé de igualdade da militância e da vida afetiva. Do entusiasmático engajamento homossexual.

É no seu apaixonado tom de confissão que o diretor Antonio Cadengue embarca, criando uma encenação que é um tratado romântico das emoções. Comprometido com uma beleza que passa pela sensualidade, dá tratamento de escultura aos belos corpos jovens e tratamento pictórico às cenas. Adepto da força do radical, do caloroso, não teme nem a pieguice nem o kitsch. É disso que seu lirismo se alimenta. Sua cena é uma esquizofrênica mistura de desaforado desejo de épater com uma declaração de amor pela vida" (1991, p. 6).

Tanto o texto de Cadengue quanto a crítica de Maria Lúcia Pereira parecem demonstrar que, no pensamento do encenador, em suas intenções e opções estéticoideológicas, subjaz uma leitura filtrada, crítica e amorosa, das teses de "Sobre o conceito de história", de Walter Benjamin, como se o pensador alemão fosse seu livro de cabeceira, lido diversas vezes antes do domínio do sonho, de modo a atuar sob seu pensamento e práxis teatrais como uma presença constante, porém espectral, diluída em 
visões e imagens concretizadas na cena. Sua sensibilidade aos apelos da História no Presente não distingue as lutas "pelas coisas brutas e materiais" - como frequentemente faz o materialismo histórico - daquelas pelas coisas "refinadas e espirituais". É como se o encenador dissesse ao seu público recifense de 1992 que "O cronista que narra os acontecimentos, sem distinguir entre os grandes e os pequenos, leva em conta a verdade de que nada do que um dia aconteceu pode ser considerado perdido para a história. Sem dúvida, somente a humanidade redimida poderá apropriar-se totalmente do seu passado. Isso quer dizer: somente para a humanidade redimida o passado é citável, em cada um dos seus momentos" (BENJAMIN, 1994, p. 223).

A história como redenção materializa-se no pensamento (e na atuação de seu encenador e da Companhia Teatro de Seraphim como um todo) deste espetáculo como um "voltar a querer e resgatar o que foi sufocado todos esses anos: um projeto coletivo" (CADENGUE, 1992b). Essa declaração do encenador atesta também sua vinculação com uma parte da história do teatro brasileiro, ligada à contracultura e ao tropicalismo, e que teve no Teatro Oficina o seu iniciador e principal representante: "Nós queremos acordar as forças das pessoas para elas voltarem a querer" (CORRÊA, 1998, p. 213).

\section{A vertigem das máscaras}

Na perspectiva da Existência em que a Vida se realiza no teatro, e o teatro é a própria vida, percebe-se o desenvolver das noções do duplo e da máscara em Artaud e na poética do grupo, ou seja, da vida enquanto artifício. Nessa chave, dois outros dramaturgos caros a CTS ganham destaque: Luigi Pirandello e Jean Genet. Ao final do projeto cultural Seraphins Revisões, ${ }^{3}$ em 1992, Cadengue publica um artigo no Jornal do Commercio, intitulado "Seraphins: encontrar-se":

No jogo que no palco se instaura, as quatro montagens teceram desvendamentos e, ao mesmo tempo, aprofundaram os artifícios próprios do teatro, na intenção de pôr a nu as máscaras: das sociais às metafísicas. Esta ideia nos obsessiona e determina em muito a escolha de nosso repertório e de nossa práxis.

Envolver-se tanto com o teatro como o fazemos - e vimos fazendo - remete-nos sem que queiramos, a um texto de Pirandello, Trovarsi, onde a personagem central do enredo, uma atriz, se realiza na imagem de cada uma das personagens que interpreta, vivendo intensamente a ficção - dentro e fora do palco - num intraduzível processo de transfiguração. Sem o teatro, enfim, 
ela não existe. Suas últimas falas na peça nos dizem: "Verdade é somente que é preciso criar-se, criar! E assim somente nos encontramos". Fazemos nossas estas palavras, por traduzir toda busca de encontro conosco mesmo e com os outros - razão de nosso trabalho. Mas não se conclua que nosso projeto implica numa estéril estetização da vida, mas na tentativa de construí-la como ininterrupto projeto de decifração de nossa contemporaneidade e mesmo de sua transformação (1992c).

Logo no primeiro parágrafo, o encenador destaca a intenção de pôr a nu as máscaras: das sociais às metafísicas. De fato, esta é uma ideia recorrente na poética da CTS, no que diz respeito à exibição vertiginosa das máscaras, seu constante processo de desvelamento. Revelação no sentido não exatamente de mostrar nossa "verdadeira face", mas da exposição do objeto em si: a máscara, enquanto nossa realidade intrínseca, nossa verdade mais profunda, tanto ao nível individual quanto ao social. Este é o desvelamento da e pela máscara, segundo a CTS. Essa noção da máscara, do disfarce e do artifício, está relacionada com a concepção de pluralidade do ser humano. Aspecto central da obra de Luigi Pirandello, autor a quem Cadengue faz referência logo em seguida nesse artigo, identificando-o de modo espelhar a própria identidade-máscara da CTS.

Segundo Anatol Rosenfeld, tratando da questão da máscara na obra de Pirandello, “A vida social impõe ao indivíduo uma forma fixa, tornada em máscara. O fluxo da existência necessita desta fixação para não se dissolver em caos, mas ao mesmo tempo o papel imposto ou adotado estrangula e sufoca o movimento da vida" (1976, p. 12). A razão então impõe ficções, falsas ilusões, que se absorvem no decurso da vida, mas que, aos poucos, adquirem uma forma rígida, artificial e opressora. Porém, essa máscara também se torna parte essencial da vida. Ela passa a expressar "uma verdade essencial que os homens não conseguem dizer nem viver na vida cotidiana, mas que podem atingir no exercício do teatro" (DORT, 1977, p. 237). Este é o ponto de contato entre o pensamento de Pirandello, Artaud e o teatro de Antonio Cadengue e seus seres afins: a máscara como perseguição de uma verdade do ser humano e, ao mesmo tempo, como uma afirmação da vida. No artigo de Cadengue, talvez isto fique mais claro quando ele diz, através das palavras de Pirandello, que nós nos encontramos no momento em que criamos, ou melhor, em que nos criamos: o "criar-se" ressoa na ideia de reconstrução do homem de Artaud. A máscara, nesse sentido, é um trabalho de investigação sobre si mesmo, e também de reelaboração do indivíduo. 
A Companhia Teatro de Seraphim manifesta também o seu gosto pelo teatro enquanto cerimônia. Essa compreensão do teatro converge, neste momento, para Genet. Conforme Bernard Dort, tanto para o dramaturgo quanto para Artaud, "trata-se de restituir à representação teatral o seu caráter de cerimônia, de transformá-la num ato" (DORT, 1977, p. 230). Genet, assim como Pirandello, é um autor de predileção de Cadengue, já encenado pelo diretor em 1988, e que é retomado pela CTS com a montagem de Os biombos, em 1995. ${ }^{4}$ Para além dessa montagem de Os biombos, a estética de Genet encontra-se presente em outros espetáculos da CTS, como Senhora dos afogados (1993), O alienista (1996), Sobrados e mocambos (1998) e A filha do teatro (2007), em que se percebe uma estética do disfarce e das suas cerimônias, refletida nessas diversas cenas, porém em diferentes perspectivas: arquetípicas, dramáticas, épicas ou parodísticas.

Todavia, as aproximações entre Artaud e Genet são limitadas, visto que, enquanto o primeiro renega toda a tradição do teatro ocidental; o segundo a valoriza, levando-a até os seus limites, a ponto de esgotar-se, sem nada pretender significar. Nesse aspecto, a Seraphim aproxima-se de Artaud e afasta-se de Genet. Ainda que este jogo sem limites de representação genetiano muito agrade a Cadengue, nunca o seu teatro é desprovido de uma tentativa de ressignificação do mundo e da arte. Nunca uma estetização da vida. Há sempre uma busca de compreensão do homem, da sociedade e do teatro, mesmo que a partir de uma vertigem das máscaras, pois, para Cadengue, são elas que oferecem a medida das diversas possibilidades do ser humano e do fenômeno teatral.

O teatro da representação de Jean Genet chega a uma situação de paroxismo em Os biombos. Nesta peça, o procedimento repete-se: o teatro representa a si mesmo. Porém, graças aos personagens de Saïd e Leila, Genet questiona o seu próprio teatro, no momento em que estes rejeitam a sua transformação em imagens tal qual ocorre com os demais personagens da peça quando seguem para o mundo dos mortos. No teatro de Genet, não existem personagens ou seres reais, mas apenas reflexos, imagens projetadas daquilo que o homem e a sociedade criam. Não há nem vida, nem morte, apenas representação. Saïd e Leila, em um ato de alta traição a Genet e ao mundo a que pertencem (a Argélia), percorrem um caminho inverso, descendente. Não se afirmam como imagens. Pelo contrário, negam-se constantemente: “Com todas as suas forças, 
recusam a se fixarem, a se transformarem em alguma coisa. Para eles, trata-se de 'ir até o fim': não perpetuar uma imagem, mas destruir todas as imagens que possamos fazer deles” (DORT, 1977, p. 239-240). No programa do espetáculo, Cadengue diz:

Genet escreveu uma história que se bifurca em muitas outras, [...] mas a história de Saïd permaneceu como leitmotiv da adaptação e da própria encenação. O motivo é simples: ao fazer a apologia de Saïd, da sua traição à causa política e social do seu país, Genet enfatiza que a substituição de um poder por outro significa a repetição - ou a cópia - da estrutura anterior. Portanto, Saïd compreende - ou quase - que deve lutar por conta própria e não por uma causa, mesmo ao preço de mergulhar na degradação, na abjeção. Interessa-lhe sobretudo trair: traição que implica um ato extremamente desonroso em nossa sociedade. Ou seja, se "tudo vira canção" ou "samba" ou "pizza", é melhor "apodrecer cada vez mais para apodrecer o mundo", como diz Saïd (1995).

Aqui, é claro um "engajamento" político-social em relação aos níveis de corrupção de uma sociedade e, particularmente, do Brasil. A destruição das máscaras sociais e existenciais - promovida por Saïd, Leila e Cadengue pressupõe um retorno à individualidade. E, ao repetir as palavras de Saïd, de que é preciso "apodrecer o mundo", Cadengue retoma o projeto artaudiano de renovação do homem através do próprio Mal. A metáfora da peste parece estar onipresente nas ideias desse texto; isto é, do Mal como um vírus que destrói por dentro, cabendo ao teatro deflagrar sua epidemia, como uma peste, para que da destruição e do caos algo novo possa surgir. Uma revolução pelo indivíduo, tendo em foco todo um sistema social.

O teatro de Jean Genet ganha novas configurações em outras montagens da CTS. Genet é deglutido, como diz o próprio encenador: "Tremo de alegria: eu comi Jean Genet!" (1995). E, nessa devoração, novas máscaras surgem, quer dizer, outras identidades-máscaras. Metamorfoses deste conceito inicial. De modo explícito, pelo menos, em dois espetáculos: Sobrados \& mocambos, de Hermilo Borba Filho (1998), e Churchi blues, de João Silvério Trevisan (2001). Ambos sob a direção de Cadengue

No primeiro, "uma peça segundo sugestões da obra de Gilberto Freyre nem sempre seguidas pelo Autor", o encenador encontra o leitmotiv do espetáculo a partir da hipótese de uma insólita intertextualidade desta peça de Hermilo Borba Filho com Os biombos, de Jean Genet. Tal hipótese dá-se em função da utilização de recursos épicos (não apenas os do teatro brechtiano) da peça, repleta de quadros independentes, sem aprisionar-se em uma ordem cronológica e espacial. Essa construção confere-lhe a 
impressão de uma "incompletude dramatúrgica", do mesmo modo como ocorre em Os biombos, conforme diz o encenador no texto do programa. Por isso, Cadengue acredita que o texto genetiano "é o principal intertexto de Sobrados e mocambos", em um "cruzamento impudico', ou como diria Oswald de Andrade, um 'ato de deglutição", (1998). Em outras palavras: uma devoração antropofágica, ao seu modo. É por meio desse cruzamento que ele intenciona efetivar sua leitura do Brasil patriarcal, para compreender este Brasil contemporâneo de 1998. É nesse "despudor" que ele cruza Hermilo Borba Filho e Gilberto Freyre com Brecht e Genet, apostando "na pluralidade, nos empréstimos culturais, sem almejar sínteses, mas prontos a desocultar o obscuro. Chamar a atenção para o inabitual e, assim, construir um painel caleidoscópico do Brasil, repleto de máscaras-identidades, desconstruindo-as com o olhar crítico - o nosso e o do espectador" (CADENGUE, 1998).

No segundo espetáculo, acompanha-se a trajetória de um índio da Amazônia, Churchi, que corre paralela à história do país, em uma investigação da "questão da identidade, do ser ou não ser brasileiro, do massacre individual, da intervenção brutal do Estado na esfera do indivíduo" (CADENGUE, 2001, p. 120). Sob diferentes tempos, ambientes e estéticas, os temas da identidade e da máscara, do que é ser brasileiro, da individualidade, são a tônica desses dois espetáculos. Percebe-se uma discussão sobre o ser humano, a sociedade e a cultura brasileira de modo intrínseco, em que se toma a cultura enquanto protesto. Ou seja, um pensamento estético-político que procura interrogar constantemente sobre o ser brasileiro. Talvez seja possível compreender as ideias teatrais e políticas deste grupo por meio das palavras de seu encenador:

Eu sou urbano. Cosmopolita. O que eu faço é uma psicanálise cultural. E não faço por modismo, nem pra aquilo ser devorado pelo 'sul maravilha'. O que as pessoas do sul e do sudeste esperam de nós é sempre um Antonio Nóbrega. Aliás, excelente performer. A imagem que eles esperam é sempre aquilo que supõem ser ou ter a cara do Nordeste. Esta cara eu não quero ter. Porque ser brasileiro é sempre ser outro, como dizia Paulo Emílio Salles Gomes. É a identidade de não ter identidade, essa máscara em que me percebo e percebo em nós brasileiros, essa maleabilidade, essa plástica, que somos nós. E querem sempre nos dar uma máscara permanente. E foi contra essa máscara que eu acabei me insurgindo ao longo desses anos. E acho que nessa questão tem um diálogo enorme com o teatro, que é ser o que não se é. Então acho que eu junto diversas discussões naquilo que eu faço (2001, p. 114-115). 
No que concerne à máscara e à identidade, Cadengue demonstra absorver completamente o pensamento de Genet e a postura de Saïd, que se nega a compactuar com as imagens-máscaras que se projetam sobre ele. Cadengue faz da máscara um jogo sinuoso, uma vertigem, de desvelamento e sobreposição de novas máscaras que, para ele, são a própria identidade brasileira e, por extensão, o teatro. Faz da máscara a essência da cultura brasileira, e só a partir dela é que se pode compreender o que é o ser brasileiro. Novamente Pirandello. É pela representação que nos encontramos.

\section{Referências}

APRESENTAÇÃO. In: COMPANHIA TEATRO DE SERAPHIM. Seraphins Revisões. Recife, Teatro Barreto Júnior, 1992. Programa. [Arquivo Companhia Teatro de Seraphim].

ARTAUD, Antonin. O teatro e o seu duplo. 2. ed. Trad. e posfácio Teixeira Coelho. São Paulo: Martins Fontes, 1999.

BENJAMIN, Walter. Sobre o conceito da história. In: Magia e técnica, arte e política: ensaios sobre literatura e história da cultura. Trad. Sérgio Paulo Rouanet. Prefácio Jeanne Marie Gagnebin. 7. ed. São Paulo: Brasiliense, 1994, p. 221-232.

BRECHT, Bertolt. Estudos sobre teatro. Trad. Fiama Pais Brandão. Rio de Janeiro: Nova Fronteira, 1978.

CADENGUE, Antonio. Proposta de encenação. In: Em nome do desejo. Recife, 1992a. Projeto de montagem, [s.p.]. [Arquivo Companhia Teatro de Seraphim].

A lira dos vinte anos: memórias e sonhos de uma geração. In: COMPANHIA TEATRO DE SERAPHIM. Seraphins Revisões. Recife, Teatro Barreto Júnior, 1992b. Programa. [Arquivo Companhia Teatro de Seraphim].

Seraphins: encontrar-se. Jornal do Commercio, Recife, p. 6, 27 jun. 1992c.

Confissões I ou Como era gostoso o meu francês. In: COMPANHIA TEATRO DE SERAPHIM. Os biombos. Direção Antonio Cadengue. Recife, Teatro Barreto Júnior, 1995. Programa. [Arquivo Companhia Teatro de Seraphim]. 
. Noite, noites. In: HOSPITAL ULYSSES PERNAMBUCANO/ CICLO ILUMINURAS/ COMPANHIA TEATRO DE SERAPHIM. Noite escura. Direção Antonio Cadengue. Recife, Capela do Hospital Ulysses Pernambucano, jun. 1997. Programa. [Arquivo Companhia Teatro de Seraphim].

Da identidade e da máscara ou Tableaux vivant em ruínas. In: COMPANHIA TEATRO DE SERAPHIM. Sobrados e mocambos. Direção Antonio Cadengue. Recife, Teatro Barreto Júnior, 1998. Programa. [Arquivo Companhia Teatro de Seraphim].

. Antonio Cadengue: fogo e fôlego, Folhetim, Rio de Janeiro, Teatro do Pequeno Gesto, n. 11, p. 96-120, set.-dez. 2001. Entrevista concedida a Fátima Saadi, Antonio Guedes, Doris Rollemberg e Walter Lima Torres.

CASTRI, Massimo. Por un teatro político - Piscator, Brecht, Artaud. Trad. María Romero. Madrid: AKAL Editor, 1978.

CORRÊA, José Celso Martinez. Lição de voltar a querer. In: Primeiro ato: cadernos, depoimentos, entrevistas (1958-1974). Seleção, organização e notas Ana Helena Camargo de Staal. São Paulo: Ed. 34, 1998, p. 211-218.

DORT, Bernard. O teatro e sua realidade. Trad. Fernando Peixoto. São Paulo: Perspectiva, 1977.

FELÍ́CIO, Vera Lúcia. A procura da lucidez em Artaud. São Paulo: Perspectiva: Fapesp, 1996.

MOURA, George. A Companhia Teatro de Séraphin. In: COMPANHIA TEATRO DE SERAPHIM. Heliogábalo \& eu. Recife, 1990, [s.p.].

PEREIRA, Maria Lúcia. Lirismo radical. Jornal da Paraíba, Campina Grande, p. 6, 30 jul. 1991.

ROSENFELD, Anatol. Texto/contexto. 3. ed. São Paulo: Perspectiva, 1976.

VIRMAUX, Alain. Artaud e o teatro. Trad. Carlos Eugênio Marcondes Moura. 2. ed. São Paulo: Perspectiva, 2000.

\footnotetext{
${ }^{1}$ No final deste texto, informam-se ainda os integrantes da companhia à época: "Nós, seres afins: Almir Rodrigues, Aníbal Santiago, Antonio Cadengue, George Moura, João Denys, Lúcia Machado, Manuel Carlos, Marcus Vinícius, Yêda Bezerra de Mello e outros seres...”. Dois anos depois, a CTS legaliza-se enquanto empresa com os seguintes sócio-fundadores: Antonio Edson Cadengue, Marcus Vinícius de Pinho e Souza, Lúcia Machado Barbosa, Manuel Carlos de Araújo, Anibal Santiago Silva e Augusto Farias Tiburtius.

2 "Uma paixão nos une: O Teatro. Precisamente por isso somos seres afins - SERAPHINS" (APRESENTAÇÃO, 1992).
} 


\begin{abstract}
${ }^{3}$ Projeto Cultural que faz uma retrospectiva de quatro montagens da CTS (Heliogábalo \& eu, 1990; Em nome do desejo, 1990; O jardim das cerejeiras, 1990; A lira dos vinte anos, 1991); produz um documentário sobre a companhia, dirigido por George Moura e Alexandre Figueirôa; realiza uma exposição de cartazes, fotos, programa, projetos de cenários e figurinos, maquetes e figurinos, além de promover duas oficinas, uma de interpretação para os próprios membros da companhia, ministrada por Maria Lúcia Pereira, e outra de crítica teatral, aberta ao público, oferecida por George Moura e Maria Lúcia Pereira. Nas palavras do grupo, o Seraphins Revisões "é o resultado de uma psicanálise cultural que vimos exercitando internamente e que, agora, pretendemos exorcizar, como uma maneira de darmos um salto qualitativo na trajetória que, por extensão, reflete criticamente a própria cultura teatral pernambucana, nos dias de hoje" (APRESENTAÇÃO, 1992).
\end{abstract}

${ }^{4}$ Antonio Cadengue encena de Luigi Pirandello Esta noite se improvisa, em 1977, pela Companhia Praxis Dramática, e em 1988, de Jean Genet, O balcão, com os alunos do Curso de Formação do Ator da UFPE. Ambos os dramaturgos encontram-se, portanto, na trajetória do encenador, antecedendo o surgimento da Companhia Teatro de Seraphim. 